\title{
Wavelet based denoising of power quality events for characterization
}

\author{
D. Saxena" ${ }^{* 1}$, S.N. Singh ${ }^{+}$and K.S. Verma ${ }^{\#}$ \\ *Department of Electrical and Electronics Engineering, I.I.E.T Bareilly (UP), INDIA. (Email: diptisx@gmail.com) \\ ${ }^{+}$Department of Electrical Engineering, I.I.T Kanpur, Kanpur (UP), INDIA. (Email: snsingh@iitk.ac.in) \\ * Department of Electrical Engineering, K.N.I.T Sultanpur (UP), INDIA. (Email: ksv211@rediffmail.com)
}

\begin{abstract}
The effectiveness of wavelet transform (WT) methods for analyzing different power quality (PQ) events with or without noise has been demonstrated in this paper. Multi-resolution signal decomposition based on discrete WT is used to localize and to classify different power quality disturbances. The energy distribution at different levels using MRA is unique for a disturbance and can be used as a feature for automatic classification of the power quality events. The PQ event duration and energy distribution of pure sine voltage wave, voltage sag, swell, transients, harmonics, impulse, notching, fluctuation and flicker are obtained using wavelet transform. The presence of noise degrades the detection capability of wavelet based method and therefore effect of noise on different signal is analyzed. The noise corrupted signal is de-noised using different wavelets and the effectiveness of the wavelets in denoising is demonstrated.
\end{abstract}

Keywords: Power Quality, Discrete Wavelet Transform, Daubechies, Multi Resolution Analysis, Denoising.

\section{Introduction}

In the emerging power systems, power quality (PQ) issues have attained considerable attention in the last decades due to increased penetration of power electronics based loads and/or microprocessor based controlled loads. On one hand these devices introduce power quality problem and on other hand these devices mal-operate due to the induced power quality problems. A PQ problem can be defined as being "any power problem manifested in voltage, current and/or frequency deviations that result in failure or mal-operation of customer equipment". The disturbance in voltage, frequency and/or current may lead to serious damage to the load equipments (Bollen, 2000). Large penetration of power electronics based controllers and devices along with restructuring of the electric power industry and small-scale distributed generation require more stringent demand on the quality of electric power supplied to the customers (Arrillaga, et al., 2000a; Arrillaga, et al., 2000b; Dugan et al., 2003).

In early days, power quality (Martzloff et al., 1998,) issues were concerned with the power system transient arising due to switching and lightning surges, induction furnace and other cyclic loads. Increased interconnection, widespread use of power electronics devices and fast control schemes in electrical power networks have brought many technical and economic advantages, but these have also introduced new challenges to the power engineers (Burke et al., 1990; Domijan et al., 1993). The power quality problems are treated differently by the utilities, equipment manufacturers, and customers. Utilities treat PQ from the system reliability point of view. Equipment manufacturers, on the other hand, consider PQ as being that level of power supply allowing for proper operation of their equipment, whereas customers consider good PQ that ensures the continuous running of processes, operations and business.

PQ disturbances/events cover a broad frequency range with significantly different magnitude variations and can be stationary or non-stationary. The on-line detection and identification of disturbances is essential to know the sources and causes of such disturbances for appropriate mitigation actions. A feasible approach to achieve this goal is to incorporate detection capabilities into

\footnotetext{
${ }^{1}$ Corresponding author. Tel: +91 - 9410261368
} 
monitoring equipment so that the events of interest can be recognized, captured and classified automatically. Hence, good performance monitoring equipment must be capable of detecting, localizing and classifying PQ events for minimizing their impact by devising suitable corrective and preventive measures.

Wavelet transform (WT) has emerged as a powerful signal processing tool used for power quality analysis (Pillay et al., 1996; Santoso et al., 1996; Robertson et al., 1996; Tunaboylu et al., 1996; Angrisani et al., 1996). The WT has the capability to analyze different power quality problems simultaneously in both time and frequency domain, hence giving the time frequency representation of signal like the short time Fourier transform (STFT). Unlike the STFT which uses a fixed window function, the wavelet transform makes use of a varied time frequency window, whose length depends on the frequency analyzed using long windows at low frequencies and short windows at high frequencies (Rioul et al., 1991). Therefore, the WT at low frequency provides accurate frequency resolution and poor time location, and at high frequency, WT gives accurate time location and bad frequency resolution. This feature of WT makes it very effective for signals such as voltage sags and transient over-voltages.

Wavelet based online disturbance detection for power quality applications are efficient as compared to conventional approaches in terms of speed and precision discrimination in the type of transient event (Karimi et al., 2000). In addition to detection of PQ events, wavelet transform is also effective in power system protection (Charri et al., 1996), detection of high impedance faults (Michalik et al., 2006) and PQ data compression (Santoso et al., 1997).

Noise present in the power quality signals has been the biggest hurdle in wavelet-based detection and time localization of PQ events. It has been observed the adverse effect of noise on wavelet and other residual based PQ monitoring and demonstrated that the performance of these techniques in detecting the disturbances would be greatly degraded, due to the difficulty in distinguishing the noise from the disturbances. Few papers (Mallat, 1989),( Hamid et al. , 2002; Ribeiro et al., 2007) which use WT denoising for compression of PQ waveform are available in literature but these do not discuss the impact of these techniques on detection and feature extraction.

Practically, electromagnetic noise is generated in every device that generates, consumes, or transmits power. Besides degrading the detection capability of wavelet and other higher time resolution based PQ monitoring systems it also hinders the recovery of important information from the captured waveform for time localization and classification of the disturbances.

In this paper, the effectiveness of wavelet transform methods for analyzing different power quality events has been investigated. The starting time, end time and duration of power quality problem along with the energy function has been obtained. The effectiveness of wavelet transform methods for analyzing different power quality events with noise has also been presented in this paper. To see the usefulness of wavelet based denoising techniques, different wavelets are considered and analyzed on different power quality events such as voltage sag, voltage swell, high frequency transients and harmonics.

\section{Wavelet Transform and Multi-Resolution Analysis}

Fourier analysis consists of breaking up a signal into sine waves of various frequencies. Similarly, wavelet analysis is the breaking up of a signal into shifted and scaled versions of the original (or mother) wavelet. The resulting wavelets, called daughter wavelets, are localized both in time and frequency. Thus, wavelet transform provides a local representation of signal in both time and frequency unlike Fourier transform which gives a global representation of signal in terms of frequency. Continuous wavelet transform (CWT), wavelet series (WS) and discrete wavelet transform (DWT) are three ways by which wavelet transform can be implemented.

Continuous wavelet transform of the signal $x(t)$ using the analysis wavelet $\psi($.$) can be written as$

$$
C W T_{x}^{\psi}(a, b)=\Psi_{x}^{\psi}(a, b)=\frac{1}{\sqrt{|a|}} \int_{t} f(t) \psi^{*}\left(\frac{t-b}{a}\right) d t
$$

where $a$ is scale parameter, $b$ is translation parameter and $1 / \sqrt{ } a$ is a normalization constant, $\psi$ is the mother wavelet. All kernels are obtained by translating (shifting) and/or scaling the mother wavelet. The oscillatory frequency and the length of wavelet is decided by the scale parameter, $a$, and the shifting position of wavelet is determined by the translation parameter, $b$.

Discrete wavelet transform is implemented using discrete values of the scaling parameter and the translation parameter. This is achieved by replacing $a$ with $a_{0}^{m}$ and $b$ with $n b_{0} a_{0}^{m}$ where $m$ is the translation step indicating frequency localization and $n$ is scaling step indicating time localization.

$$
D W T(m, n)=\frac{1}{\sqrt[m]{a_{0}}} \sum_{k} f(k) \Psi\left(\frac{k-n b_{0} a_{0}^{m}}{a_{o}^{m}}\right)
$$

Wavelet transform is called a dyadic-orthonormal wavelet transform when $a_{0}=2$ and $b_{0}=1$ and this results in a very efficient algorithm, known as multi-resolution signal decomposition technique. The multi-resolution analysis (MRA) introduced by Mallat (Mallat, 1989) decomposes a signal into scale with different time and frequency resolution. In MRA, a signal $\mathrm{f}(\mathrm{t})$ can be completely decomposed into its detailed version (high frequency components) and smoothed/ approximated versions. The wavelet function serving as high pass filter with filter coefficients $\mathrm{g}(\mathrm{n})$, generates the detailed version of the distorted signal, while the 
scaling function associated with low pass filter with filter coefficient $h(n)$, generates the approximated version of the distorted signal. Thus, by using MRA high frequency transients can be easily analyzed in presence of low frequency components such as non-stationary and non-periodic wide-band signals. MRA can be implemented by a set of successive filter banks as shown in Figure 1.

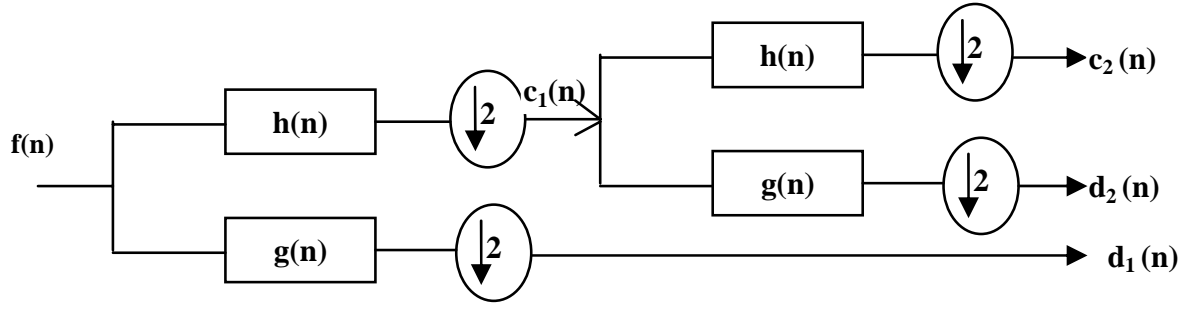

Figure1. Decomposition of $\mathrm{f}(\mathrm{n})$ into two scales

The $h(n)$ and $g(n)$ are the low pass and high pass filters. If $f(n)$ is the discrete time signal, from MRA, the decomposed signal at scale-1 are $c_{1}(n)$ and $d_{1}(n)$, where $c_{1}(n)$ is the smoothed version of the original signal, and $d_{1}(n)$ is the detailed version of the original signal down-sampled by a factor 2 . Since both the high pass filter and low pass filters are half band, this decomposition halves the time resolution since now only half the number of sample characterize the entire signal. However, this operation doubles the frequency resolution since the frequency band of signal now spans only half the previous frequency band, effectively reducing the uncertainty in the frequency by half. The next higher scale decomposition is now based on the signal $c_{1}(n)$, which decomposes it further into $c_{2}(n)$ and $d_{2}(n)$. At each scale, the filtering and sub sampling result in half the number of samples and thus half the time resolution and double the frequency resolution.

The choice of mother wavelet plays a significant role in detecting and localizing various types of disturbances. Daubechies' wavelets with 4, 6, 8, and 10 filter coefficients work well in most of the disturbance detection cases. At the lowest scale (scale 1), the mother wavelet is the most localized in time and oscillates most rapidly within a very short period of time. As the wavelet goes to higher scales, the analyzing wavelets become less localized in time and it oscillates less due to the dilation nature of the wavelet transform analysis. As a result of higher scale signal decomposition, the fast and short power quality disturbances will be detected at lower scales, whereas slow and long power quality disturbances will be detected at higher scales. Hence, both fast and slow power quality disturbances can be detected. Since Daub4 has the least number of filter coefficients and it gives the shortest support, Daub4 has been used in the work.

\section{Wavelet Based Feature Extraction}

DWT decomposes the input signal into a group of different frequency levels, each corresponding to a particular frequency band. Therefore, the wavelet technique discriminates disturbances from the original signal, and then analyses them separately. The discontinuities in the signal due to disturbances in the form of sharp edges, transitions and jumps are reflected in the higher frequency bands. Thus, any change in the smoothness of signal can be detected and localized at the finer resolution level. The wavelets coefficients of the finer resolution level will have high magnitude at the start and the end point of disturbance, when DWT is used to analyze a distorted signal through 1 level decomposition of MRA. Therefore the start $t_{s}$ and the end time $t_{e}$ can easily be obtained from the variation in wavelets coefficients and the time duration $t_{t}$ of the disturbance can hence be calculated as

$t_{t}=\left|t_{e}-t_{s}\right|$

Next important task after the detection and localization of the PQ event is the extraction of features which can be used for their classification. The squared wavelet coefficients at different resolution levels, the standard deviation and/or mean value and the maximum modulus of the wavelet coefficients at different resolution level have been used. The energy of a distorted signal can be partitioned at different resolution levels in different ways depending on the power quality problems. The energy distribution of a distorted signal can be used as a discriminatory feature for classification. The energy of a distorted signal at a resolution level $j$ is given by

$P_{j}=\sum_{i=1}^{N_{m}}\left(d_{m}(i)\right)^{2}$

where $N_{m}$ is the number of available wavelets coefficient at the resolution level $j$ 


\section{Simulation and Analysis}

\subsection{Data Generation}

The simulation data is generated in MATLAB based on the model in paper (Rodney et al., 2010). One pure sine-wave signal (frequency $=50 \mathrm{~Hz}$, amplitude 1p.u) and nine PQ disturbance signals are generated. The disturbance signal includes voltage sag, voltage swell, harmonics, low frequency transient, high frequency transient, impulse, voltage fluctuation, notching and flicker. Table 1 gives the signal generation models and their controlled parameters. A four-level decomposition of the distorted signal is carried out using db4.The detailed energy distribution up to 10-level decomposition, of each signal is also obtained.

Figures 2(a)-2(c) show the first three detailed versions of a three-level decomposition and detailed energy distribution of a pure sine wave. Any changes in the pattern of signal can be detected and localized at the finer resolution levels. As far as detection and localization is concerned, the wavelet coefficients of the first finer decomposition level of $f(t)$ are normally adequate to detect and localize any disturbance in the signal. As seen in Figure 2(b), for a pure signal, the set of coefficients at the finer first threeresolution level is zero. Since the signal is smooth the duration of disturbance could not be detected. Any changes in the signal can be detected and localized in time due to changes in the magnitude of these coefficients.

Table 1 Signal models and their parameters

\begin{tabular}{|c|c|c|}
\hline $\begin{array}{c}\text { PQ } \\
\text { disturbance }\end{array}$ & Model & Parameters \\
\hline Sine -wave & $x(t)=A \sin (\omega t)$ & $\mathrm{A}=1.0$ \\
\hline Sag & $x(t)=A\left(1-\alpha\left(u\left(t-t_{1}\right)-u\left(t-t_{2}\right)\right)\right) ; \quad t_{1}<t_{2}, u(t)=1, t \geq 0$ & $0.1 \leq \alpha \leq 0.9, T \leq t_{2}-t_{1} \leq 8 T$ \\
\hline Swell & $x(t)=A\left(1+\alpha\left(u\left(t-t_{1}\right)-u\left(t-t_{2}\right)\right)\right) ; \quad t_{1}<t_{2}, u(t)=1, t \geq 0$ & $0.1 \leq \alpha \leq 0.8, T \leq t_{2}-t_{1} \leq 8 T$ \\
\hline Harmonics & $x(t)=A\left[\sin \omega t+\alpha_{3} \sin (3 \omega t)+\alpha_{5} \sin (5 \omega t)\right]$ & $0.1 \leq \alpha_{3} \leq 0.2,0.05 \leq \alpha_{5} \leq 0.1$ \\
\hline Flicker & $x(t)=A[1+\beta \sin (\gamma \omega t)] \sin (\omega t)$ & $0.1 \leq \beta \leq 0.2,0.1 \leq \gamma \leq 0.2$ \\
\hline $\begin{array}{l}\text { Transient } \\
\text { (a) } \\
\text { High } \\
\text { Frequency } \\
\text { (b) Low } \\
\text { Frequency }\end{array}$ & $\begin{array}{l}x(t)=\sin (\omega t)+a e^{-k} \sin (b \omega t) ; \quad \text { where } k=\frac{t}{\lambda} \\
20 \leq b \leq 80 ; \text { for high frequency transeint } \\
5 \leq b \leq 20 ; \text { for low frequency transeint }\end{array}$ & $\begin{array}{l}0.1 \leq a \leq 0.9 \text { for transient period } \\
a=0 \text { otherwise } \\
0.1 \leq \lambda \leq 0.2\end{array}$ \\
\hline Fluctuation & $x(t)=(1+a \sin (b \omega t)) \sin (\omega t)$ & $0.1 \leq a \leq 0.2,0.4 \leq b \leq 0.6$ \\
\hline Notch & $x(t)=\sin (\omega t)+\left(n_{d} p v_{n}\right) \quad$ where $p=\operatorname{sgn}[\sin (\omega t+180)$ & \\
\hline $\begin{array}{l}\text { Impulsive } \\
\text { transient }\end{array}$ & $x(t)=\sin (\omega t)+\left[u_{1}\left(a \cdot e^{-\rho t_{1}}\right)\right]$ & \\
\hline
\end{tabular}

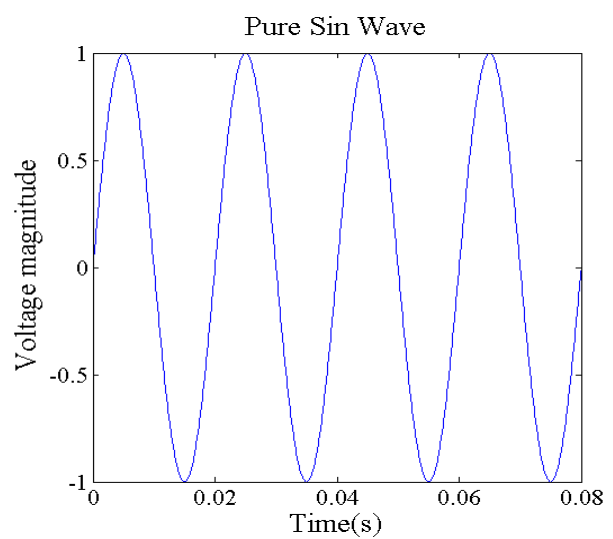

(a) Pure sine wave
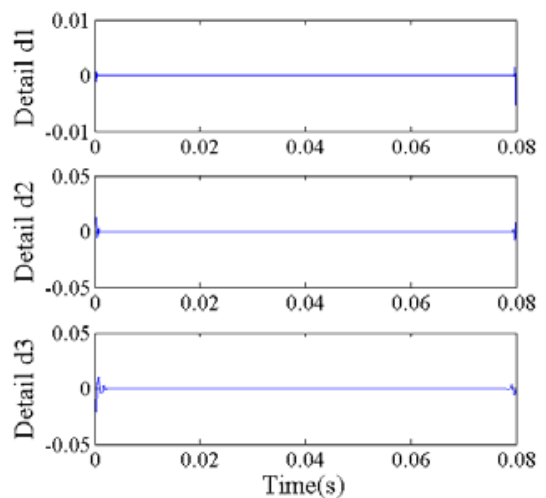

(b) Three-level decomposition of (a)

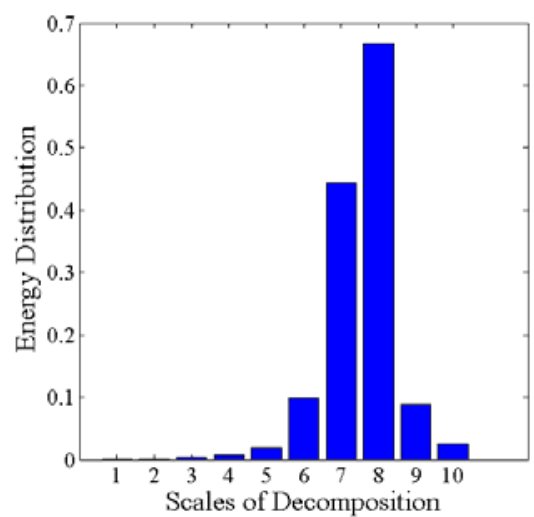

(c) Detailed energy distribution of (a) 


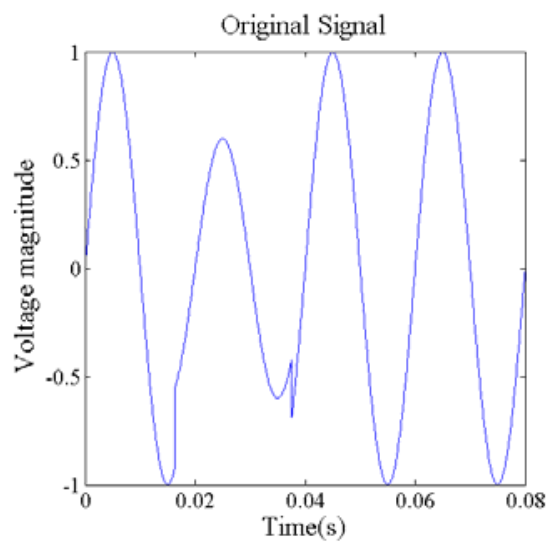

(d) Voltage sag condition

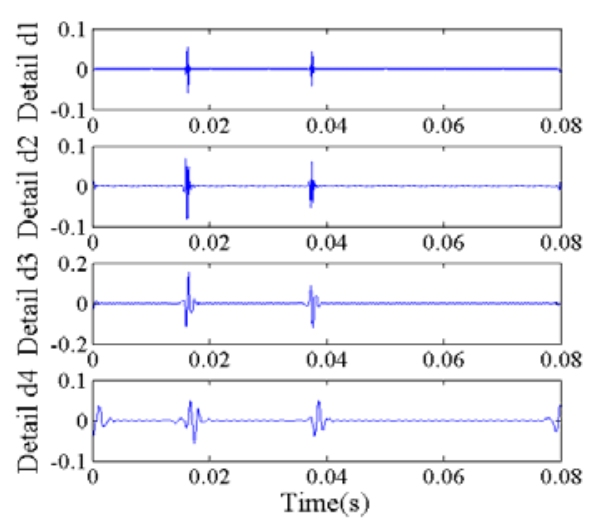

(e) Four-level decomposition of (d)

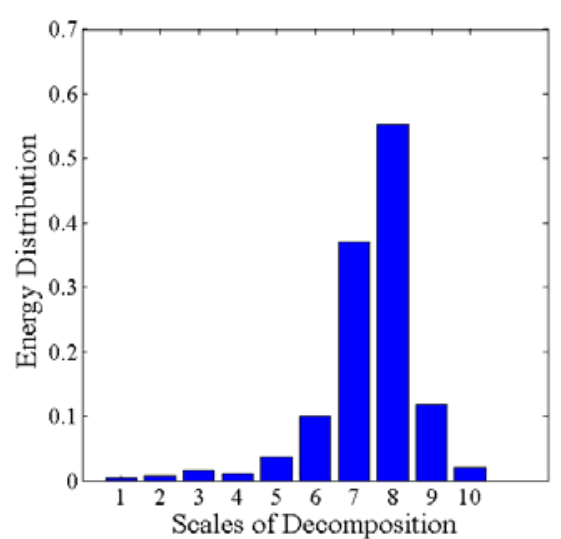

(f) Detail energy distribution of (d)

Figure 2. MRA decomposition and detailed energy distribution of a pure sine wave and voltage sag

Figures 2(d)-2(e) show the detailed version of four-level decomposition and the detailed energy distribution (P1D - P10D) of a voltage sag signal which is detected and localized at first three finer resolution levels. This is because at the lower scales, the analyzing wavelet is more localized, therefore wavelet transform picks up the severe disturbance. The starting time of the sag ts $=0.01625$ and the ending time te $=0.0375$ and hence the duration of sag phenomenon can be detected and localized in the first three detail levels

Table 2 Time information results of disturbances

\begin{tabular}{|c|c|c|}
\hline Type of Disturbance & Start $(\mathrm{sec})$ & $\begin{array}{c}\text { Duration } \\
(\mathrm{sec})\end{array}$ \\
\hline Sag & .01625 & .02125 \\
\hline Swell & .01625 & .02125 \\
\hline High Frequency transient & .00625 & .0050 \\
\hline $\begin{array}{c}\text { Low Frequency } \\
\text { Transient }\end{array}$ & .0175 & .0175 \\
\hline
\end{tabular}

The detailed version at the first three decomposition levels of a voltage swell shown in Figures 3(a)-(b) indicates that the swell can also be well detected and localized at the finer resolution levels. Figures 3(e)-3(f) show the detailed version of four-level decomposition and the detailed energy distribution $\left(\mathrm{P}_{1}{ }^{\mathrm{D}}-\mathrm{P}_{10}{ }^{\mathrm{D}}\right)$ of a low frequency transient. The duration of all the four disturbances (high frequency transient, low frequency transient, sag and swell) is determined using first level of detail and given in Table 2. These disturbances always found to have a pattern in first level information. Even though high frequency transient exists for very short duration its starting and ending time were correctly detected.

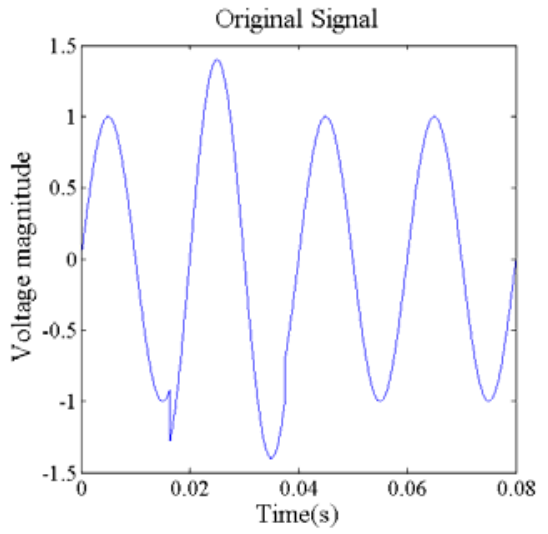

(a) Voltage swell case

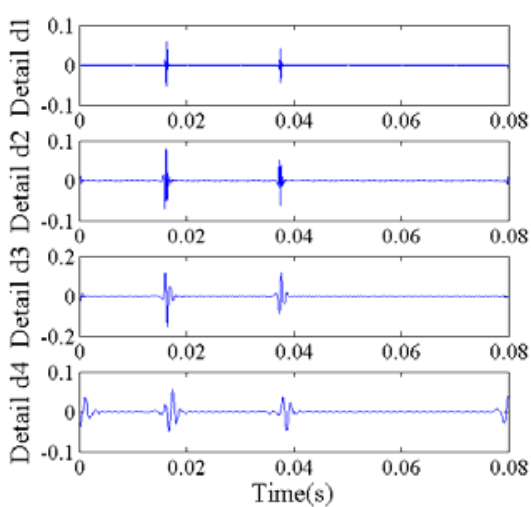

(b) Four-level decomposition of (a)

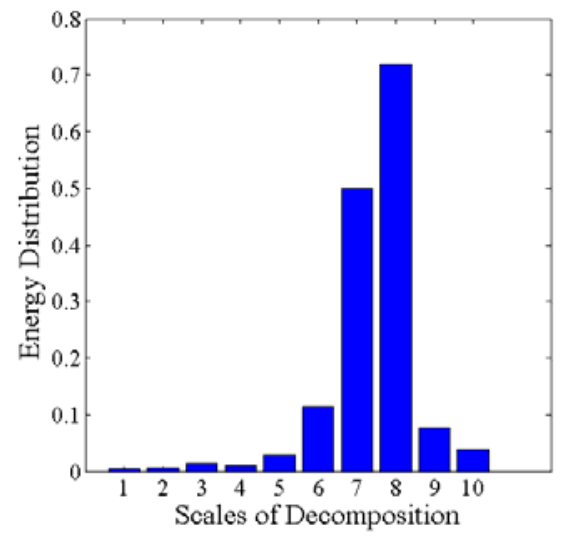

(c) Detailed energy distribution of (a) 


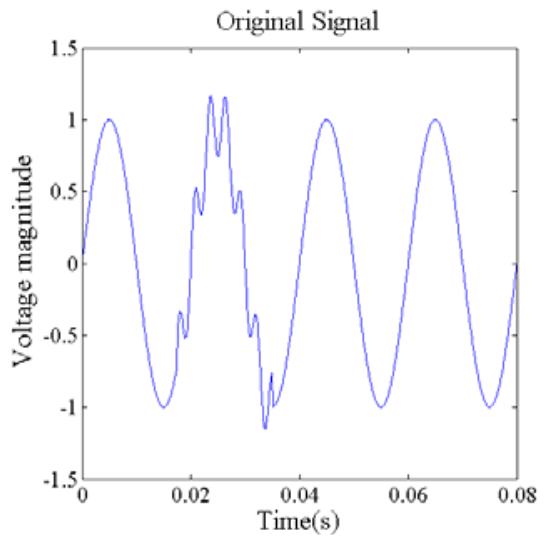

(d) Low frequency transient case

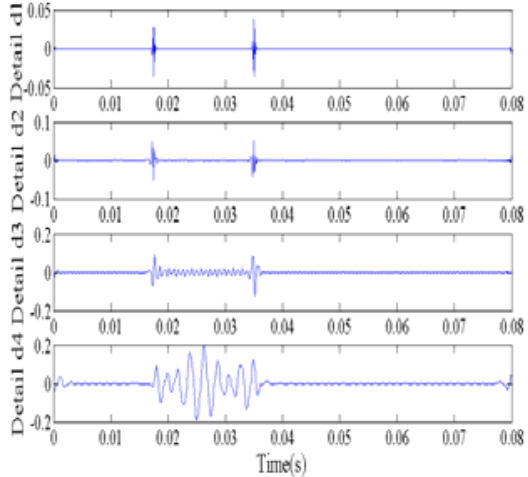

(e) Four-level decomposition of (d)

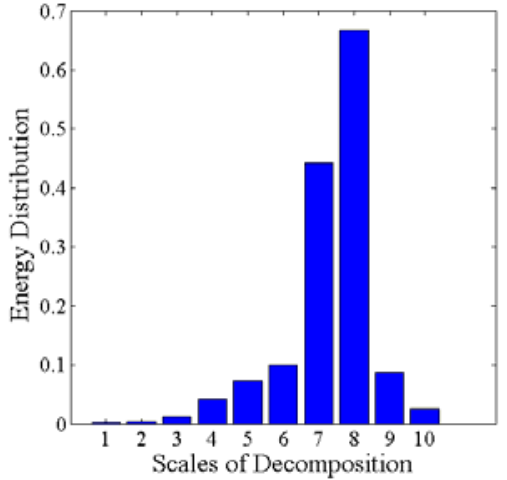

(f) Detailed energy distribution of (d)

Figure 3. MRA decomposition and detailed energy distribution of a voltage swell and a low frequency transient

Figures 4(a)-4(f) show the original signal, four-level decomposition and detailed energy distribution of high frequency transient and an impulse case. In Figure 4(e), the WTC shows the occurrence of sharp event of wavelet disturbance ie due to impulse. This is because at scale 1 , the analyzing wavelet is most localized and therefore the wavelet transform picks up the disturbance that have the most severe or most rapid transitions.

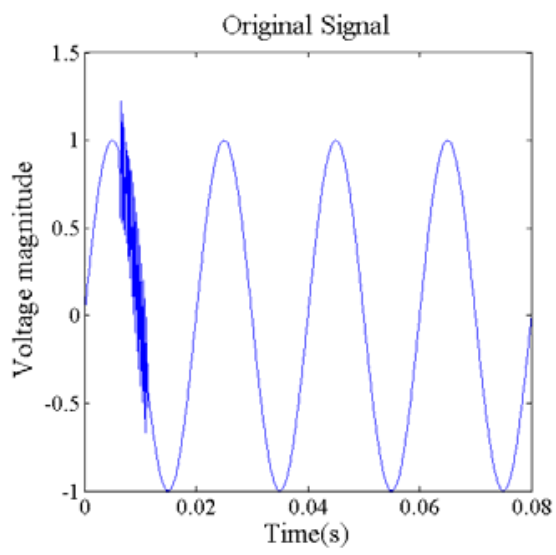

(a) High frequency transient case

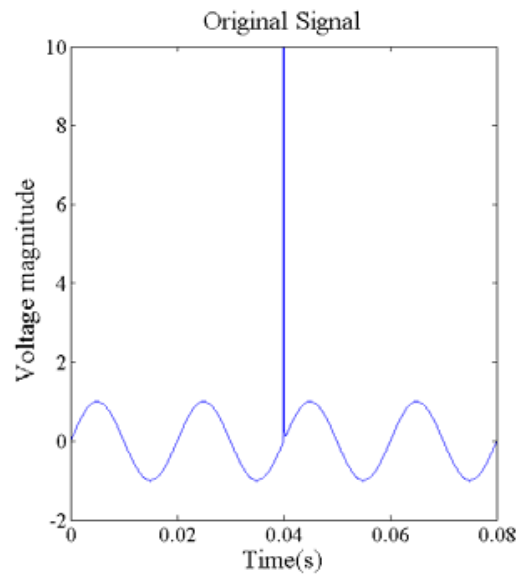

(d) Voltage impulse case

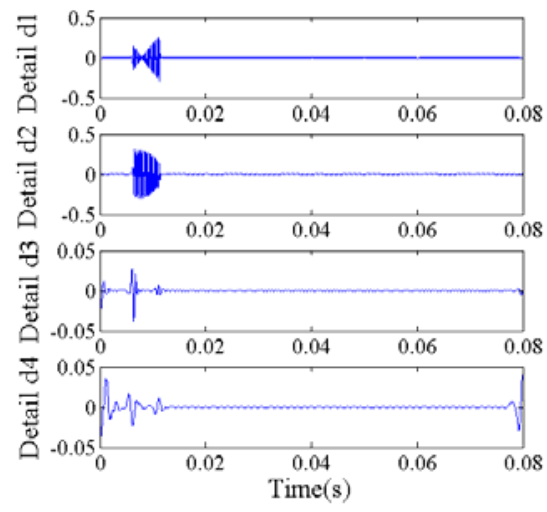

(b) Four-level decomposition of (a)
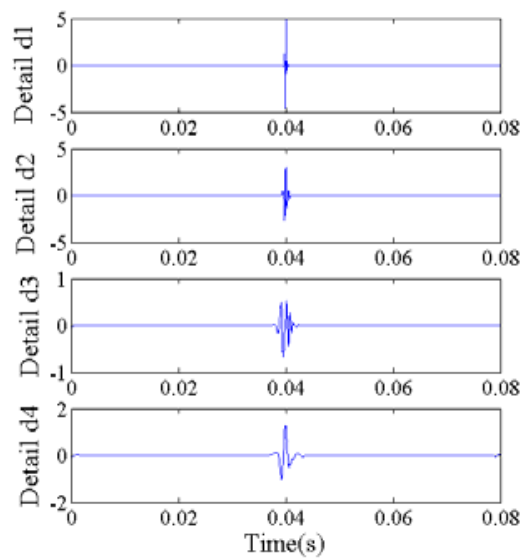

(e) Four-level decomposition of (d)

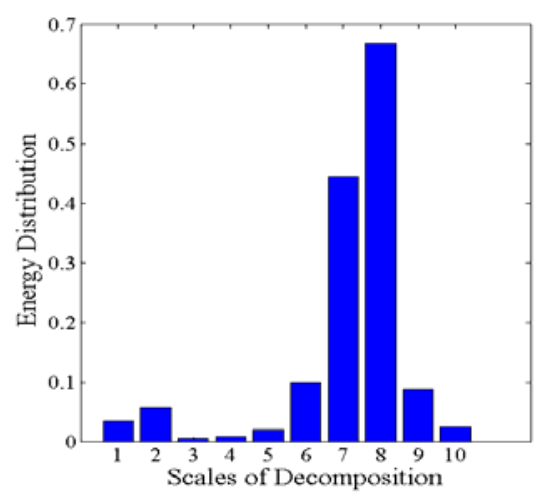

(c) Detailed energy distribution of (a)

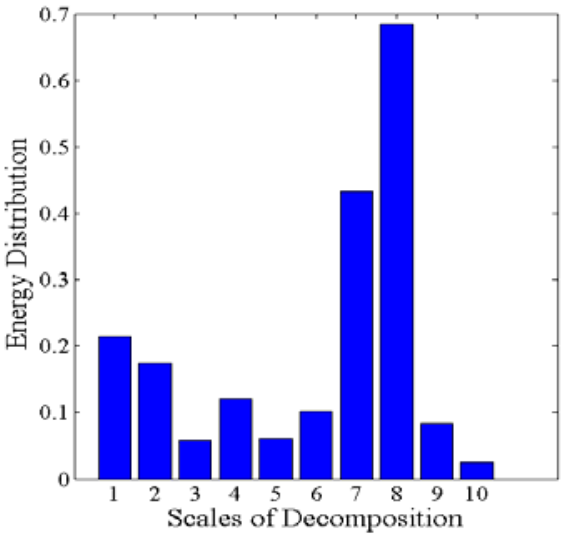

(f) Detailed energy distribution of (d)

Figure 4. MRA decomposition and detailed energy distribution of a high transient and impulse signal 


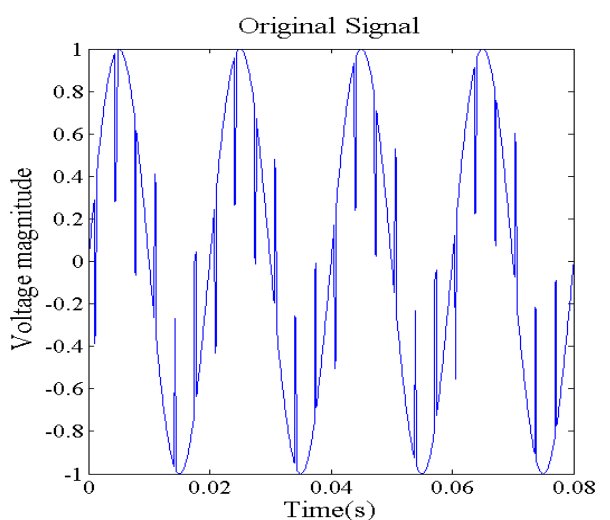

(a) Voltage notch case

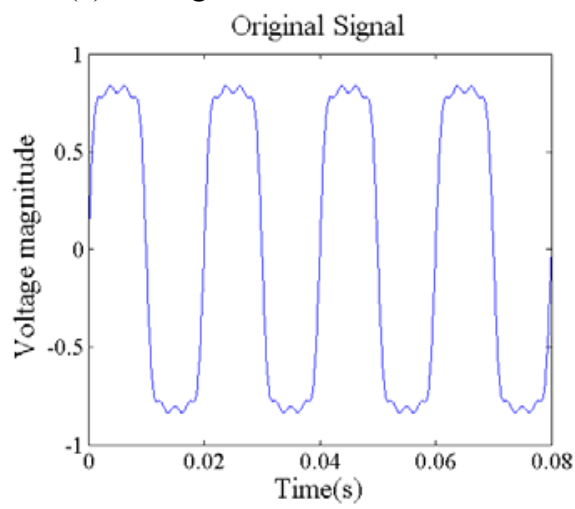

(d) Voltage harmonic case

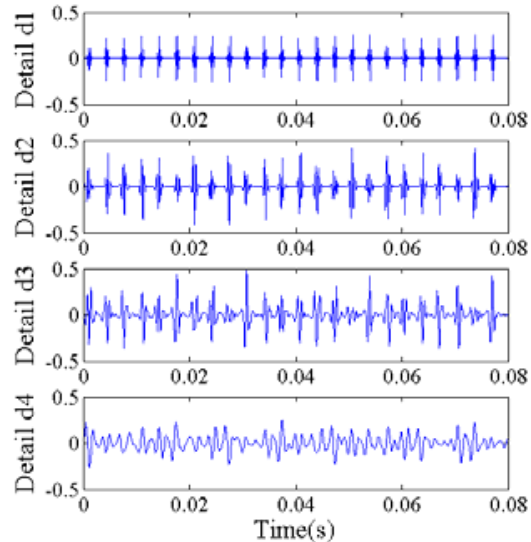

(b) Four-level decomposition of (a)

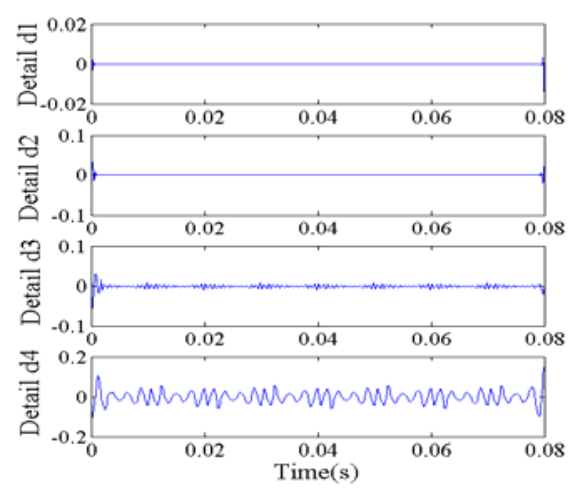

(e) Four-level decomposition of (d)

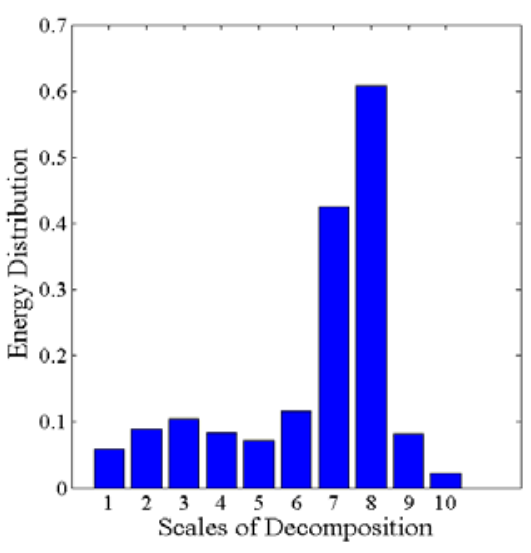

(c) Detailed energy distribution of (a)

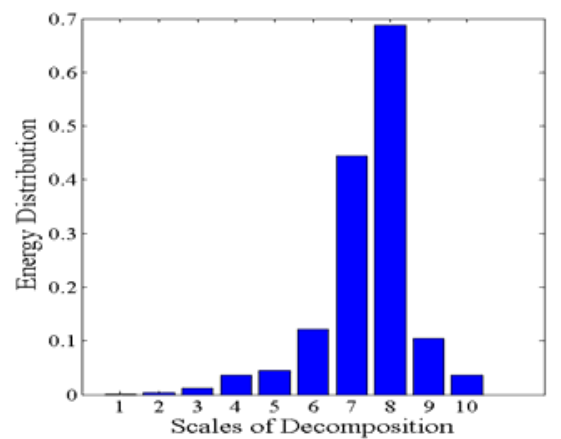

(f) Detailed energy distribution of (d)

Figure 5. MRA decomposition and detailed energy distribution of a voltage notch and harmonics

The signal, presented in Figure 5 (a), shows the occurrence of disturbance almost periodically. The detection result at scale 1 also shows (Figure 5(b)) that the disturbance indeed occurs almost periodically. The disturbance occurs as periodic impulses at scale one and the number of notches per cycle can be counted by counting the peaks ie high magnitude of WTC at scale 1. Figures 5(d)-5(f) shows the voltage signal having harmonics, MRA decomposition and detailed energy distribution, respectively.

Figure 6 shows MRA decomposition and detailed energy distribution voltage fluctuation. Voltage fluctuation, harmonics and notches are stationary disturbances, therefore no localization property can be detected at any of the finer levels. The harmonics are steady and fluctuation is considered to be intermittent so there duration is not calculated. Each disturbance has a unique detailed energy distribution. Figure 7 shows a voltage flicker and MRA decomposition along with energy distribution.

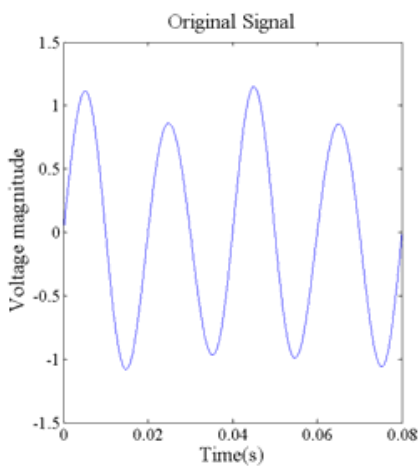

(a) Voltage fluctuation case
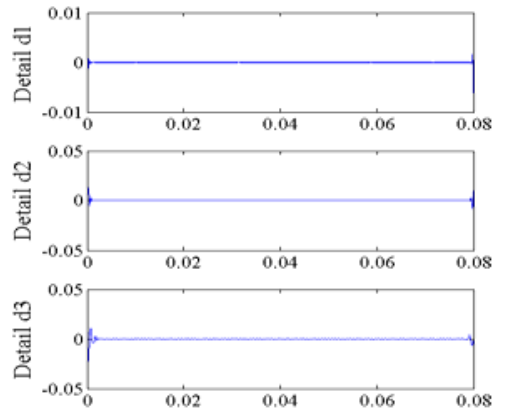

(b) Four-level decomposition of (a)
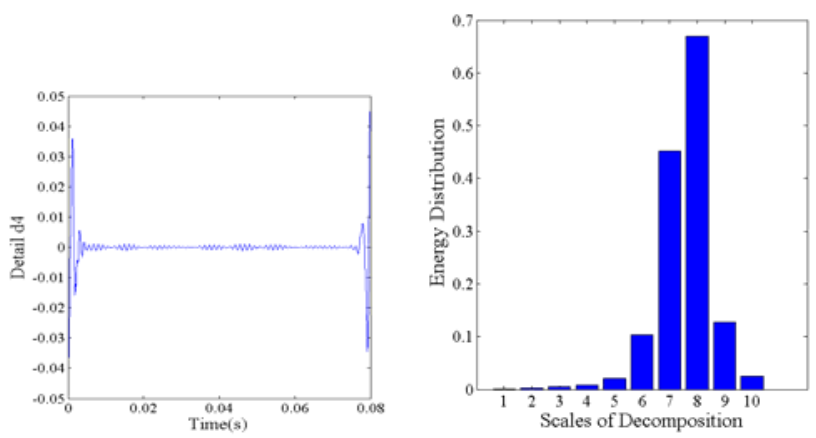

(c) Detailed energy distribution

Figure 6. MRA decomposition and detailed energy distribution of voltage fluctuation 

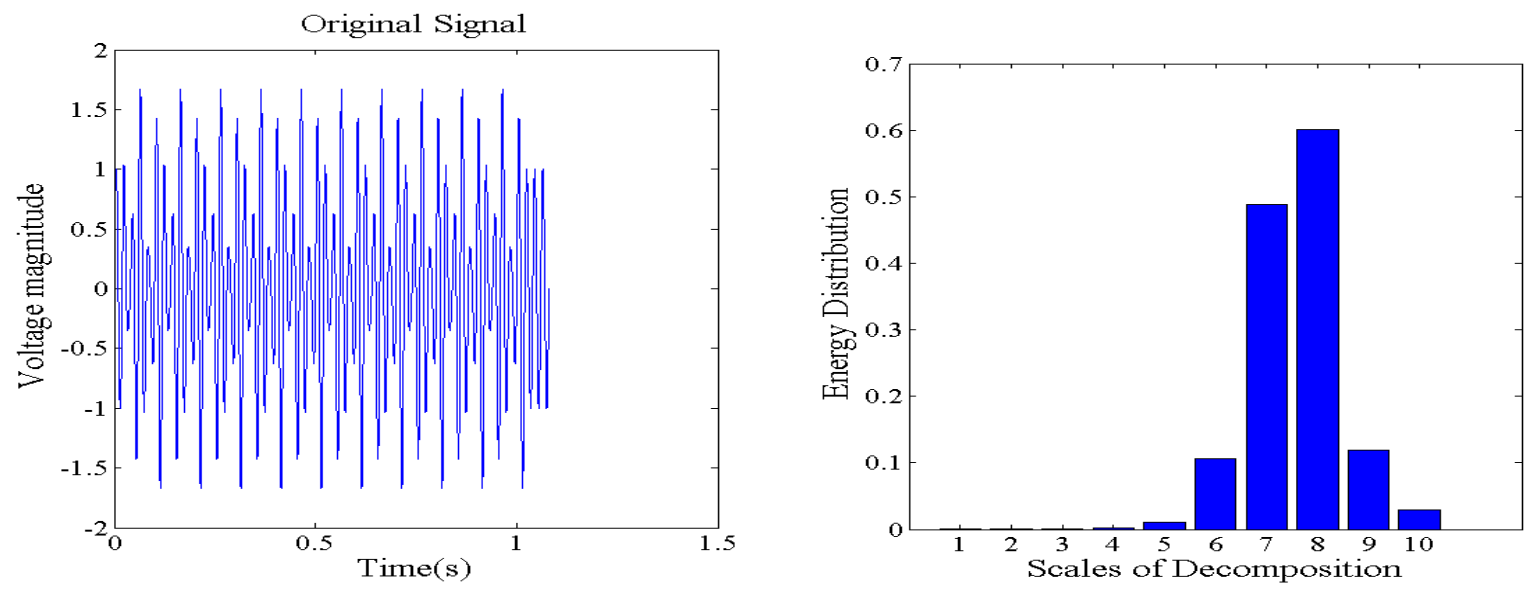

Figure 7. Flicker and its detailed energy distribution

Table 3 Energy features of distorted signals

\begin{tabular}{|l|l|l|l|l|l|l|l|l|l|l|}
\hline \multirow{2}{*}{\begin{tabular}{l} 
Signal Type \\
\cline { 2 - 11 }
\end{tabular}} & \multicolumn{9}{|l|}{ Energy features of distorted signal } \\
\cline { 2 - 11 }${ }_{1}{ }^{\mathrm{D}}$ & $\mathrm{P}_{2}{ }^{\mathrm{D}}$ & $\mathrm{P}_{3}{ }^{\mathrm{D}}$ & $\mathrm{P}_{4}{ }^{\mathrm{D}}$ & $\mathrm{P}_{5}{ }^{\mathrm{D}}$ & $\mathrm{P}_{6}{ }^{\mathrm{D}}$ & $\mathrm{P}_{7}{ }^{\mathrm{D}}$ & $\mathrm{P}_{8}{ }^{\mathrm{D}}$ & $\mathrm{P}_{9}{ }^{\mathrm{D}}$ & $\mathrm{P}_{10}{ }^{\mathrm{D}}$ \\
\hline $\begin{array}{l}0.0003 \\
\text { Pure Sine Wave }\end{array}$ & 0.00144 & .00483 & 0.00765 & 0.0195 & 0.0992 & 0.444 & 0.667 & 0.0833 & 0.0245 \\
\hline $\begin{array}{l}\text { High Fransics } \\
\text { Transients }\end{array}$ & 0.0009 & 0.00379 & .0127 & .0359 & .0452 & 0.122 & 0.444 & 0.688 & 0.105 & .0364 \\
\hline $\begin{array}{l}\text { Low Frequency } \\
\text { Transient }\end{array}$ & .0336 & .0576 & .00543 & .008 & .0194 & .0995 & 0.444 & 0.667 & .0879 & .0244 \\
\hline Sag & .00269 & .00456 & .0125 & .0411 & .073 & .0996 & 0.443 & 0.667 & .0878 & .0247 \\
\hline Swell & .00445 & .00703. & .0152 & .0107 & .0374 & 0.1 & 0.37 & 0.553 & 0.119 & .0202 \\
\hline Impulsive Transient & .00396 & .00626 & .0137 & .0103 & .0397 & 0.115 & 0.5 & 0.719 & .0764 & .0387 \\
\hline Notching & 0.215 & 0.174 & 0.0582 & 0.12 & .06 & 0.102 & 0.433 & 0.685 & .0834 & .025 \\
\hline Flicker & 0.0593 & 0.0896 & 0.105 & 0.0835 & 0.0724 & 0.116 & 0.426 & 0.608 & 0.0817 & 0.02190 \\
\hline Voltage Fluctuation & 0.0000 & 0.0004 & 0.0013 & 0.0023 & 0.017 & 0.106 & 0.488 & 0.601 & 0.119 & 0.0289 \\
\hline
\end{tabular}

From Figures 2-7, and Table 3 the important features of energy distribution can be categorized as follows:

- $\quad \mathrm{P}_{7}{ }^{\mathrm{D}}, \mathrm{P}_{8}{ }^{\mathrm{D}}$ show a great variation when sag or swell occurs.

- $\mathrm{P}_{5}{ }^{\mathrm{D}}, \mathrm{P}_{6}{ }^{\mathrm{D}}$ will show obvious variation when the voltage suffers from harmonic distortion.

- Impulse and notching energy can be seen to be distributed at several high frequency bands and

- High frequency transient can be detected in by the high value of $\mathrm{P}_{2}{ }^{\mathrm{D}}$.

The decomposition levels 9 and 10 represent the signal strength in $25-12.5 \mathrm{~Hz}$ and $12.5-6.25 \mathrm{~Hz}$ frequency bands respectively, at the chosen sampling rate of $12.8 \mathrm{kHz}$. The signal strength in these scales can be used to detect voltage flicker as the frequency associated with flicker are less than $25 \mathrm{~Hz}$ (IEEE Std-1159). In Figure 7, $\mathrm{P}_{9}{ }^{\mathrm{D}}$ shows obvious variation when the voltage suffers a transient disturbance of the low frequency elements such as flicker.

Thus, when a distorted signal contains high frequency elements, the low level energy distribution will show obvious variation and when the distorted signal contains low frequency elements the high level energy distribution will show obvious variation.

\subsection{Effect of Noise and Denoising}

In practice, signals captured by monitoring devices are often accompanied with noise thereby affecting the extraction of important features from the signal. Noise has an adverse effect on the performances of wavelet based event detection, time localization and classification schemes due to the difficulty of separating noise and the disturbances. The disturbance component of the waveform carries the most important information for detection and classification of the disturbances. When a PQ data is decomposed using wavelet transform, most of the disturbance components are reflected at higher frequency bands which are also occupied by noise. Therefore, even if the magnitude of noise present is not very high compared to fundamental component, for many PQ disturbances, it is comparable to disturbance energy at these bands. Hence, presence of noise degrades the detection capability of wavelet based PQ monitoring system. Figure 8 shows the structure of PQ monitoring system integrated with proposed 
denoising scheme. For denoising the noise corrupted signal, wavelet decomposition is performed at level 10 using various mother wavelets and a de-noised version of input signal (one- or two-dimensional) is obtained by wavelet coefficient using global positive threshold.

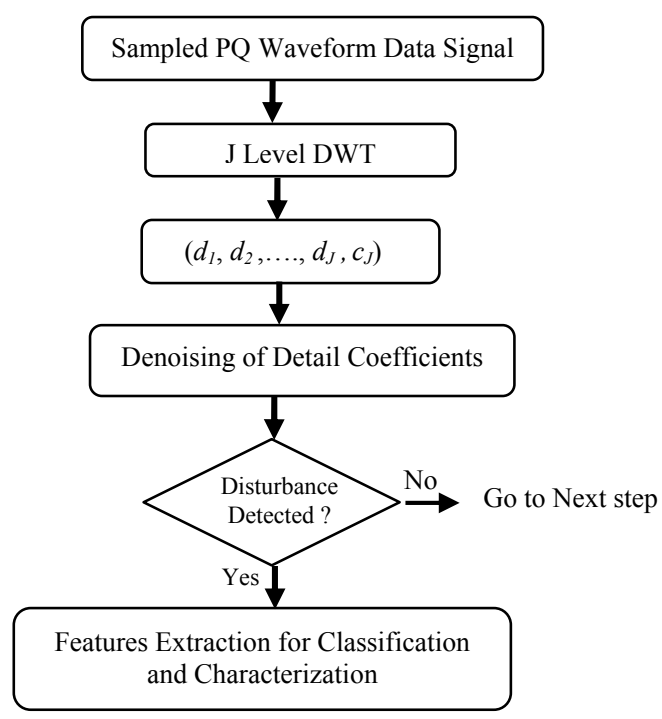

Figure 8. PQ denoising scheme

Figure 9 shows a pure sine wave contaminated with $30 \mathrm{db}$ Gaussian noise and its detailed energy distribution. As compared to pure sine wave, it can be seen that the noise has affected the energy distribution of sine wave with high values of energy in higher frequency bands. Five signals sine wave, sag, swell, high frequency transients and harmonic, mixed with $30 \mathrm{db}$ noise are simulated individually. Five different wavelets namely db4, db6, db10, sym 4 and coif4 have been used to denoise the corrupted signal. The energy distribution of the denoised signal obtained is compared with the original noisy signal using wavelet db4. It is found from the Figure 9 that addition of noise increases the values at lower level of energy distribution in the case of sine wave. But after the denoising with wavelets, this lower level energy distribution is removed but the other level values are also changed and in most of the cases, it is reduced.

Figure 10 shows the detailed energy distributions (10-level) of noisy sine wave after denoising by different wavelets. From Figure 10, it can be seen that the changes in energy levels in the $7^{\text {th }}$ an $8^{\text {th }}$ levels are not significant but at $6^{\text {th }}, 9^{\text {th }}$ and $10^{\text {th }}$ the percentage changes are significant. The energy distribution for all 10 levels for five signals with and without noise and denoised signals are given in Table 4. Figure 11 shows a voltage sag case with $30 \mathrm{db}$ Gaussian noise and its detailed energy distribution calculated using (4). It can be seen that the effect of noise introduces the energy distribution at lower levels. Energy distributions after denoising using the different five wavelets are shows in Figure 12. It can be observed that after denoising the lower level energy distributions are eliminated. However, the energy at other levels is also reduced. Comparing the different denoising wavelets, it can be seen that db6 gives better results compared to the other wavelets.
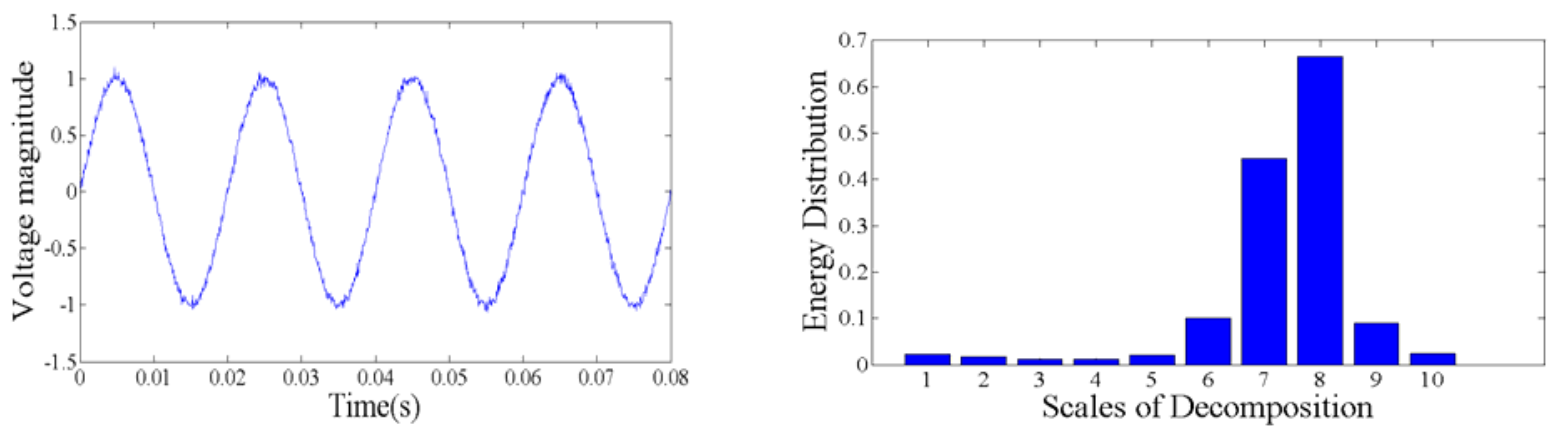

Figure 9. Sine wave with noise and its detailed energy distribution 


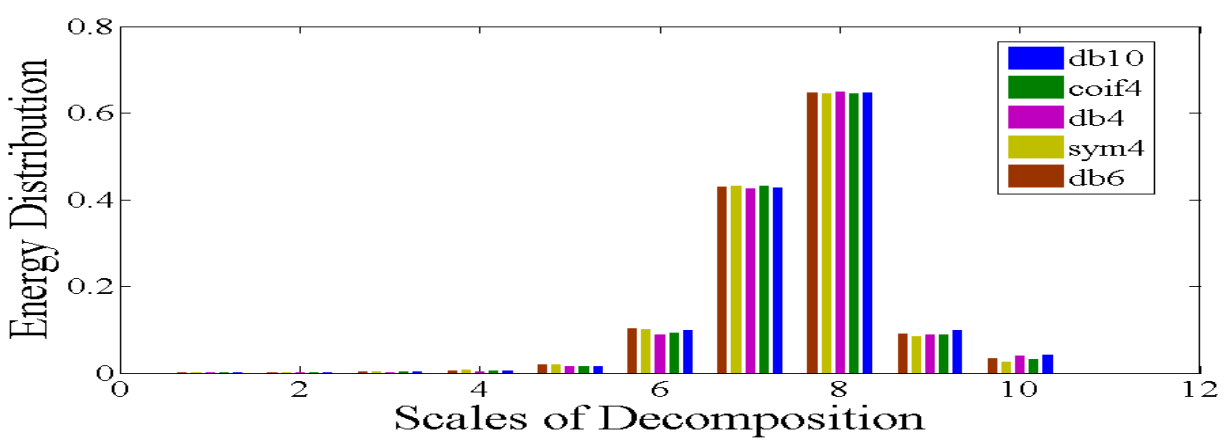

Figure 10. Detailed energy distribution Denoised sine wave with denoising wavelet db4, db6, db10, sym4, coif4
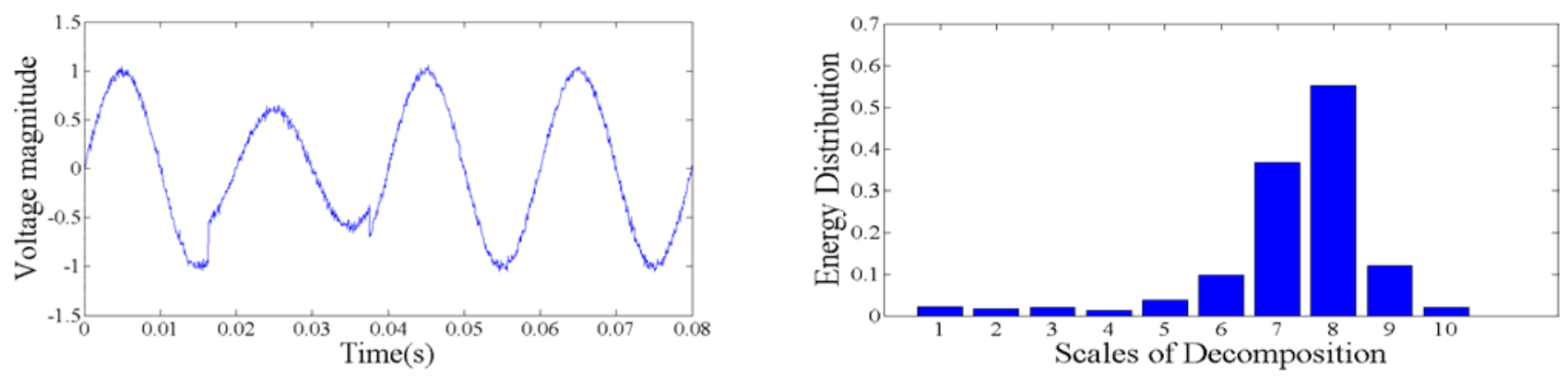

Figure 11. Sag wave with noise and its detailed energy distribution

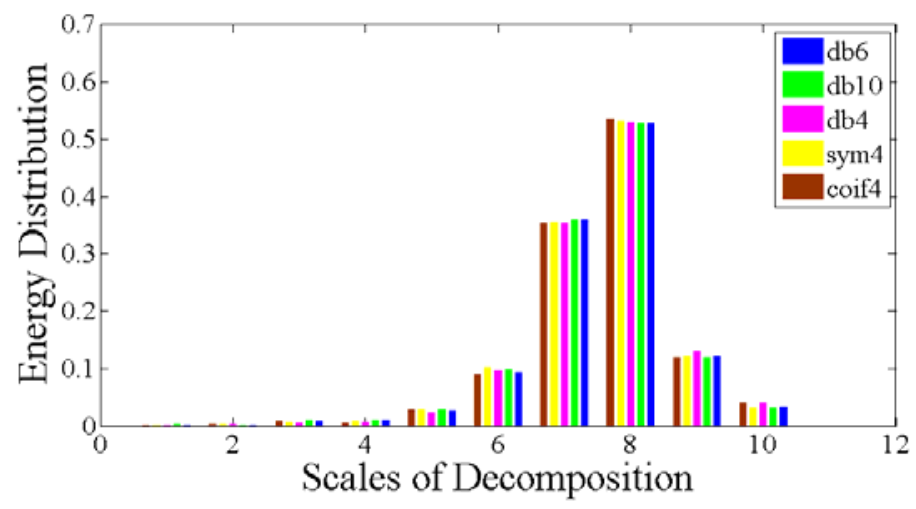

Figure 12: Detailed energy distribution Denoised sag wave with denoising wavelet db4, db6, db10, sym4, coif4

Voltage swell with noise and its detailed energy distribution is shown in Figure 13. In this case also, the effect of noise introduces the energy distribution at lower levels. Energy distributions after denoising using the different five wavelets are shows in Figure 14. It can be observed that after denoising the lower level energy distributions are eliminated. However, the energy at other levels is also reduced. Comparing the different denoising wavelets, it can be seen that db6 gives better results compared to the other wavelets.

Figure 15 shows a voltage harmonics case with $30 \mathrm{db}$ Gaussian noise and its detailed energy distribution calculated using (4). It can be seen that the effect of noise introduces the energy distribution at lower levels. Energy distributions after denoising using the different five wavelets are shows in Figure 16. It can be observed that after denoising, the lower level energy distributions are eliminated. However, the energy at other levels is also reduced.

Figure 17 shows a high frequency transient case with $30 \mathrm{db}$ Gaussian nose and its detailed energy distribution. It can be seen that the effect of noise increases the energy distribution at lower levels. It should be noted that the effect of high frequency transient can be seen at low level energy distribution even without noise. Energy distributions after denoising using the different five wavelets are shows in Figure18. 

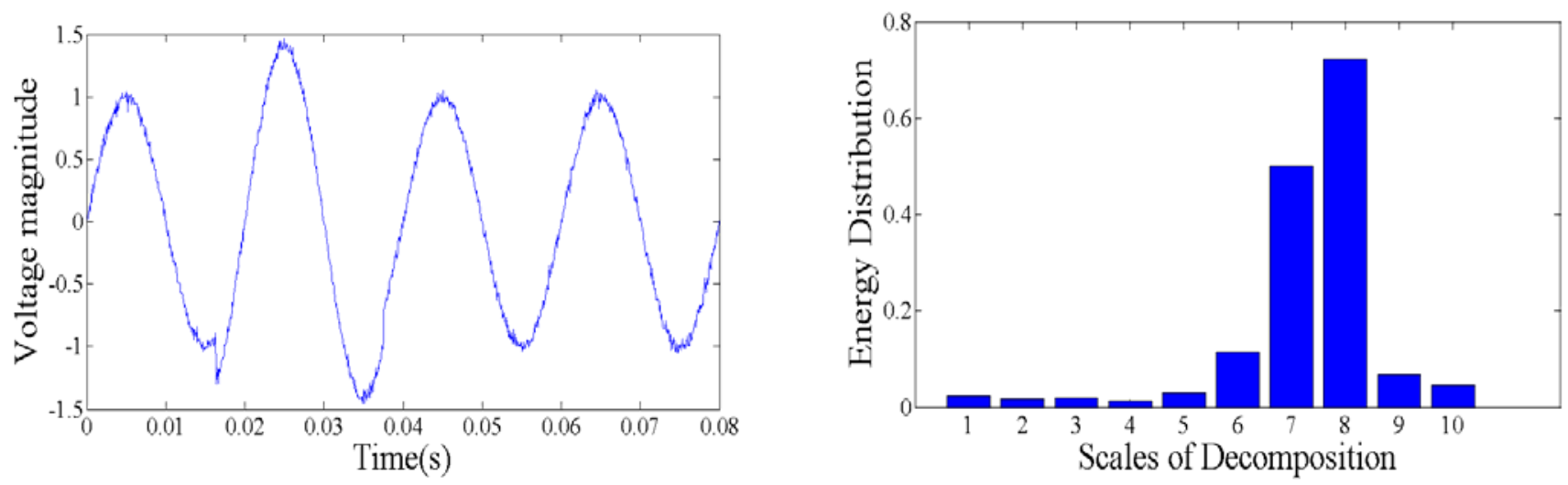

Figure 13. Swell with noise and its detailed energy distribution

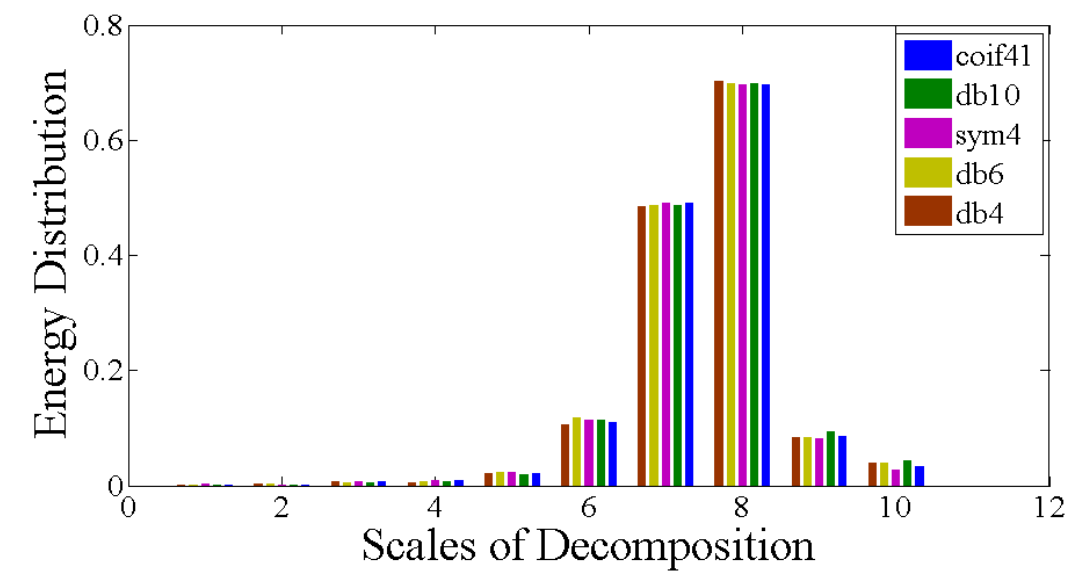

Figure14. Detailed energy distribution Denoised swell with denoising wavelet db4, db6, db10, sym4, coif4
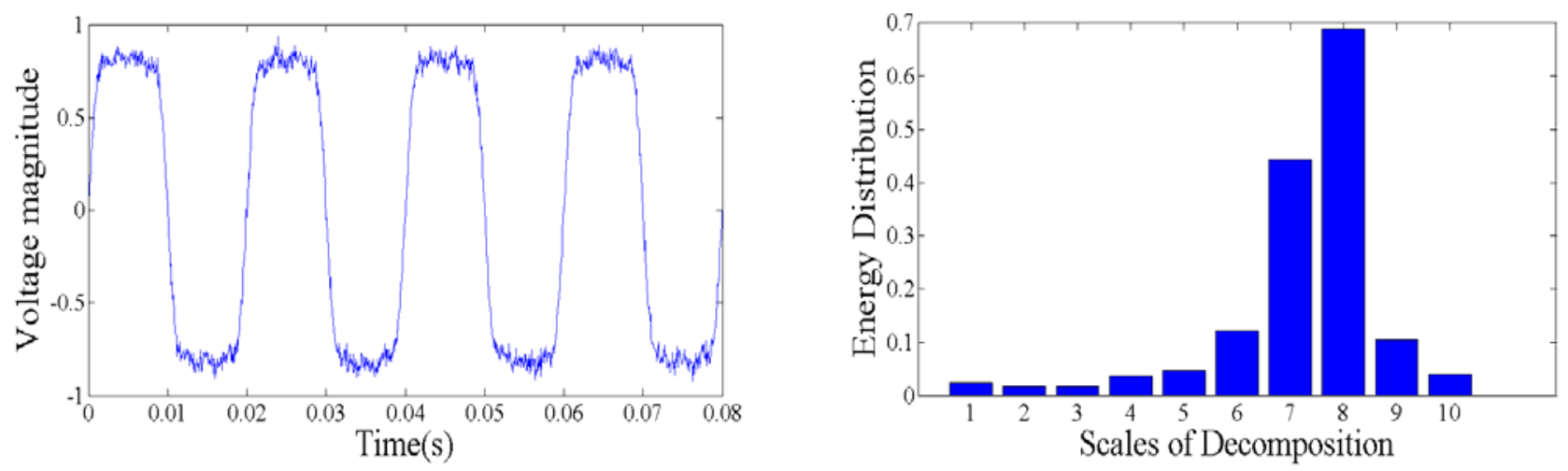

Figure15. Harmonics with noise and its detailed energy distribution

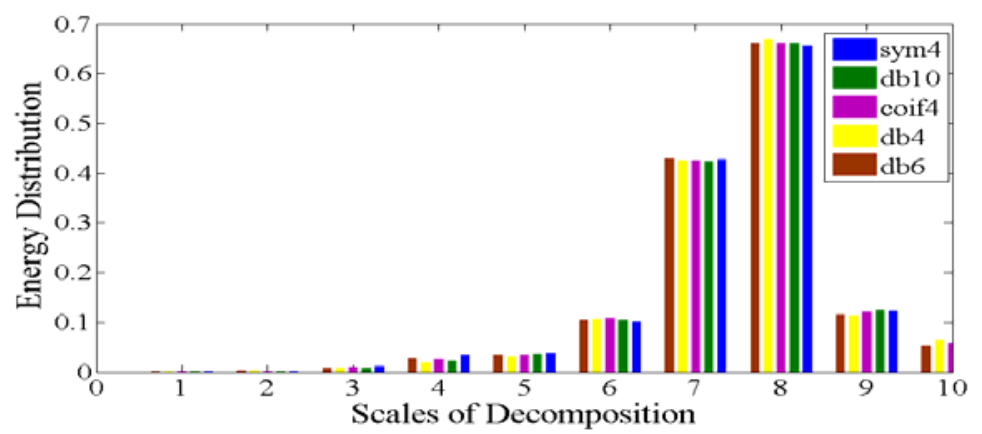

Figure16. Detailed energy distribution Denoised harmonics with denoising wavelet db4, db6, db10, sym4, coif4 

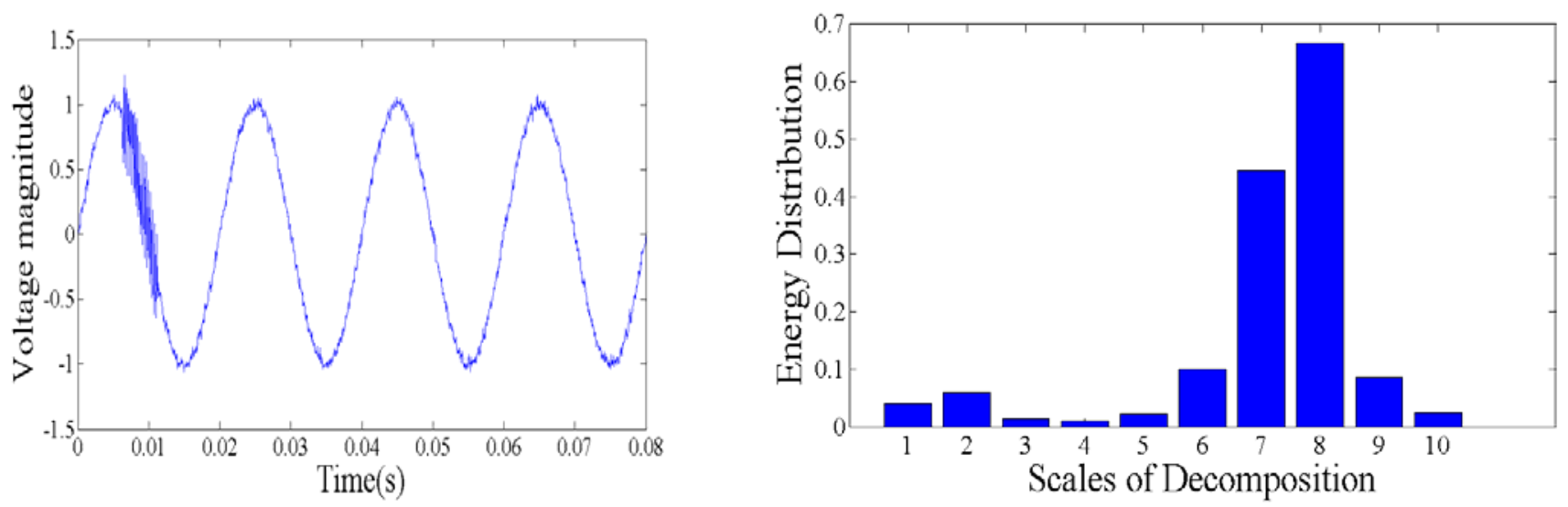

Figure17. High Frquency Transient with noise and its detailed energy distribution

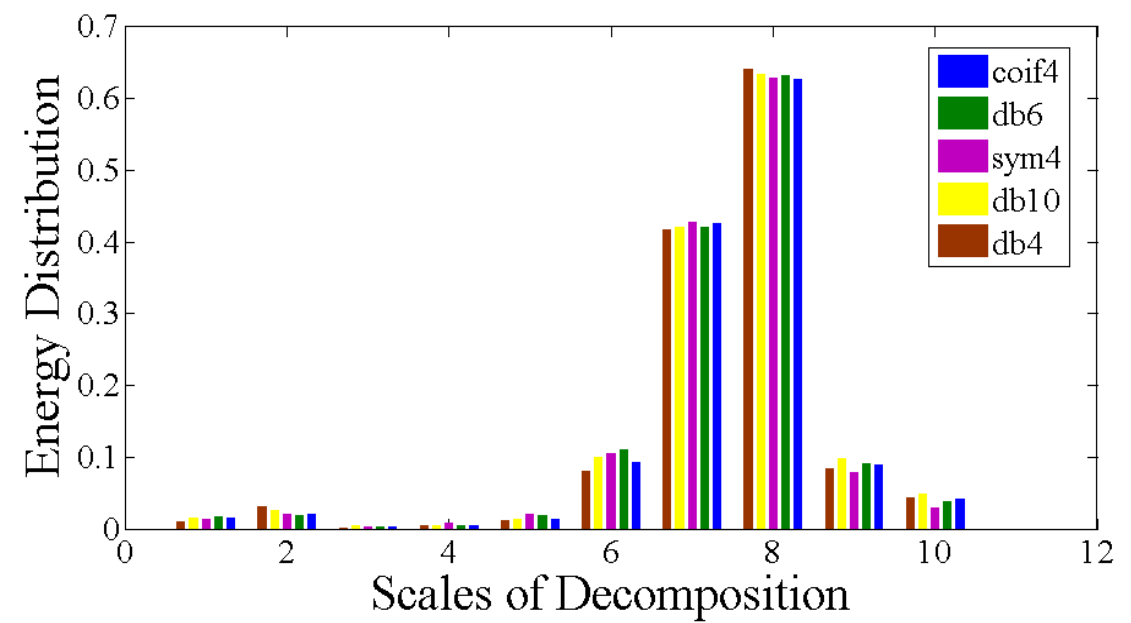

Figure18. Detailed energy distribution denoised harmonics with denoising wavelet db4, db6, db10, sym4, coif4

From Figures 9-18, it is evident that the energy of high frequency bands increases with the introduction of noise in the signal. Therefore, a signal corrupted with noise can be classified as a high frequency transient. In denoising technique the high frequency characteristics of harmonics and high frequency transient are suppressed to some extent. The denoised signal obtained using db6 is more close to the original signal in energy distribution in most of the cases as compared to other wavelets used for denoising. It can also be observed that after denoising the lower level energy distributions are eliminated. However, the energy at other levels is also reduced.

Table 4. Energy distribution of pure signal with noise and without noise

\begin{tabular}{|l|l|l|l|l|l|l|l|l|l|l|}
\hline \multirow{2}{*}{ Signals } & \multicolumn{6}{|l}{ Energy at different scales } & \multicolumn{1}{l|}{$l|l| l|l|$} \\
\cline { 2 - 11 } & $\mathrm{P}_{1}{ }^{\mathrm{D}}$ & $\mathrm{P}_{2}{ }^{\mathrm{D}}$ & $\mathrm{P}_{3}{ }^{\mathrm{D}}$ & $\mathrm{P}_{4}{ }^{\mathrm{D}}$ & $\mathrm{P}_{5}{ }^{\mathrm{D}}$ & $\mathrm{P}_{6}{ }^{\mathrm{D}}$ & $\mathrm{P}_{7}{ }^{\mathrm{D}}$ & $\mathrm{P}_{8}{ }^{\mathrm{D}}$ & $\mathrm{P}_{9}{ }^{\mathrm{D}}$ & $\mathrm{P}_{10}{ }^{\mathrm{D}}$ \\
\hline Sine without noise & $\mathbf{0 . 0 0 0 3 5}$ & $\mathbf{0 . 0 0 1 4 4}$ & $\mathbf{0 . 0 0 4 8 3}$ & $\mathbf{0 . 0 0 7 6 5}$ & $\mathbf{0 . 0 1 9 5}$ & $\mathbf{0 . 0 9 9 2}$ & $\mathbf{0 . 4 4 4}$ & $\mathbf{0 . 6 6 7}$ & $\mathbf{0 . 0 8 3 3}$ & $\mathbf{0 . 0 2 4 5}$ \\
\hline Sine with noise 30 & 0.02200 & 0.01630 & 0.01240 & 0.01160 & 0.0196 & 0.1010 & 0.444 & 0.666 & 0.0899 & 0.0240 \\
\hline Denoised using Db4 & 0.00019 & 0.00051 & 0.00151 & 0.00318 & 0.0129 & 0.0898 & 0.425 & 0.647 & 0.0928 & 0.0415 \\
\hline Denoised using Db6 & 0.00020 & 0.00070 & 0.00265 & 0.00450 & 0.0188 & 0.1030 & 0.430 & 0.646 & 0.0912 & 0.0035 \\
\hline Denoised using Db10 & 0.00020 & 0.00080 & 0.00343 & 0.00492 & 0.0150 & 0.1010 & 0.429 & 0.646 & 0.0997 & 0.3730 \\
\hline Denoised using Sym4 & 0.00030 & 0.00070 & 0.00246 & 0.00782 & 0.0182 & 0.0993 & 0.434 & 0.644 & 0.0864 & 0.0264 \\
\hline Denoised using Coif4 & 0.00001 & 0.00048 & 0.00310 & 0.00526 & 0.0157 & 0.0948 & 0.435 & 0.643 & 0.0891 & 0.0320 \\
\hline Sag without noise & $\mathbf{0 . 0 0 4 4 5}$ & $\mathbf{0 . 0 0 7 0 3}$ & $\mathbf{0 . 0 1 5 2 0}$ & $\mathbf{0 . 0 1 0 7 0}$ & $\mathbf{0 . 0 3 7 4 0}$ & $\mathbf{0 . 1 0 0 0}$ & $\mathbf{0 . 3 7 0}$ & $\mathbf{0 . 5 5 3}$ & $\mathbf{0 . 1 1 9 0}$ & $\mathbf{0 . 0 2 0 2}$ \\
\hline Sag noise 30db & 0.02330 & 0.01800 & 0.01960 & 0.01400 & 0.0369 & 0.0983 & 0.355 & 0.555 & 0.1140 & 0.0204 \\
\hline Denoised using Db4 & 0.00020 & 0.00107 & 0.00819 & 0.00533 & 0.0304 & 0.0925 & 0.355 & 0.535 & 0.1160 & 0.0321 \\
\hline Denoised using Db6 & 0.00117 & 0.00322 & 0.00758 & 0.00959 & 0.0293 & 0.1040 & 0.359 & 0.534 & 0.1180 & 0.0258 \\
\hline
\end{tabular}




\begin{tabular}{|c|c|c|c|c|c|c|c|c|c|c|}
\hline Denoised using Db10 & 0.00088 & 0.00196 & 0.00485 & 0.00696 & 0.0255 & 0.0975 & 0.356 & 0.529 & 0.1290 & 0.0398 \\
\hline Denoised using Sym4 & 0.00093 & 0.00177 & 0.00981 & 0.00980 & 0.0292 & 0.0986 & 0.359 & 0.527 & 0.1180 & 0.0346 \\
\hline Pure Swell & 0.00396 & 0.00626 & 0.01370 & 0.01030 & 0.0397 & 0.1150 & 0.500 & 0.719 & 0.0764 & 0.0387 \\
\hline Swell noise 30db & 0.02210 & 0.01650 & 0.01850 & 0.01360 & 0.0313 & 0.1130 & 0.498 & 0.719 & 0.0779 & 0.0375 \\
\hline Denoised using Db4 & 0.00020 & 0.00105 & 0.00562 & 0.00385 & 0.021 & 0.1030 & 0.484 & 0.703 & 0.0830 & 0.0434 \\
\hline Denoised using Db6 & 0.00216 & 0.00218 & 0.00499 & 0.00797 & 0.0234 & 0.1170 & 0.488 & 0.701 & 0.0778 & 0.0426 \\
\hline Denoised using Db10 & $\begin{array}{l}0.00028 \\
5\end{array}$ & 0.00114 & 0.00471 & 0.00591 & 0.0197 & 0.1110 & 0.483 & 0.698 & 0.0950 & 0.0453 \\
\hline Denoised using Sym 4 & 0.00182 & 0.00172 & 0.00826 & 0.00934 & 0.0257 & 0.1130 & 0.489 & 0.697 & 0.0820 & 0.0308 \\
\hline Denoised using Coif4 & 0.00026 & 0.00072 & 0.00573 & 0.00828 & 0.0208 & 0.1080 & 0.489 & 0.696 & 0.0861 & 0.0371 \\
\hline Harmonics & 0.00090 & 0.00379 & 0.01270 & 0.03590 & 0.0452 & 0.1220 & 0.444 & 0.688 & 0.1050 & 0.0364 \\
\hline Harmonics with noise & 0.02300 & 0.01600 & 0.01690 & 0.03620 & 0.0464 & 0.1210 & 0.444 & 0.688 & 0.1040 & 0.0405 \\
\hline Denoised using Db4 & 0.00026 & 0.00190 & 0.00736 & 0.02060 & 0.0300 & 0.1080 & 0.427 & 0.673 & 0.1070 & 0.0668 \\
\hline Denoised using Db6 & 0.00060 & 0.00220 & 0.00720 & 0.02840 & 0.0314 & 0.1040 & 0.431 & 0.665 & 0.1100 & 0.0585 \\
\hline Denoised using Db10 & 0.00030 & 0.00140 & 0.00780 & 0.02330 & 0.0352 & 0.1040 & 0.426 & 0.667 & 0.1120 & 0.0725 \\
\hline Denoised using Sym4 & 0.00070 & 0.00127 & 0.01070 & 0.03440 & 0.0359 & 0.0990 & 0.431 & 0.662 & $\begin{array}{l}0.1120 \\
0\end{array}$ & 0.0518 \\
\hline Denoised using Coif4 & 0.00041 & 0.00165 & 0.00906 & 0.02600 & 0.0354 & 0.1090 & 0.429 & 0.666 & 0.1120 & 0.0577 \\
\hline $\begin{array}{ll}\text { High } & \text { Frequency } \\
\text { Transients } & \\
\end{array}$ & 0.03360 & 0.05760 & 0.00543 & 0.00800 & 0.0194 & 0.0995 & 0.444 & 0.667 & 0.0879 & 0.0244 \\
\hline HFTR noise 30db & .054600 & 0.06540 & 0.02040 & 0.01620 & 0.0223 & 0.1030 & 0.443 & 0.666 & 0.0928 & 0.0236 \\
\hline Denoised using Db4 & 0.00974 & 0.02970 & 0.00140 & 0.00491 & 0.0101 & 0.0761 & 0.418 & 0.64 & 0.0811 & 0.0481 \\
\hline Denoised using Db6 & 0.01780 & 0.01840 & 0.00461 & 0.00464 & 0.0185 & 0.1100 & 0.422 & 0.63 & 0.0882 & 0.0395 \\
\hline Denoised using Db10 & 0.01330 & 0.02500 & 0.00252 & 0.00301 & 0.0137 & 0.0978 & 0.418 & 0.633 & 0.0977 & 0.0571 \\
\hline Denoised using Sym4 & 0.01100 & 0.01750 & 0.00273 & 0.00847 & 0.0209 & 0.1030 & 0.425 & 0.627 & 0.0691 & 0.0235 \\
\hline Denoised using Coif4 & 0.01510 & 0.01960 & 0.00171 & 0.00478 & 0.0145 & 0.0875 & 0.426 & 0.629 & 0.0798 & 0.0375 \\
\hline
\end{tabular}

\section{Conclusion}

The paper demonstrates the wavelet transform based MRA as an effective tool for the assessment and analysis of PQ events. The advantage of using wavelet and multiresolution analysis to extract features is to get very precise time information about the event. The starting and duration of sag, swell, transients can be determined using first level detail. The procedure in effect offers a good time resolution at high frequencies, and good frequency resolution at low frequencies. The energy distribution of level 10 using multi-resolution technique has been used to access the performance of the wavelets The approach is very suitable especially when the signal has high frequency component for short duration and low frequency components for long duration. Since most of the signals encountered in PQ assessment are of this type Wavelet transform method to analyze PQ disturbances proves to be much better than the other advanced digital processing techniques. The features extracted using wavelet transform can be applied as an input to a classifier for automatic classification of different PQ events. The effect of noise degrades the identification and detection capability of wavelet based power quality (PQ) method. In this paper, the five different wavelets are used to denoise the PQ signals. The presence of noise increases the energy distribution at lower levels. It is found that db6 provides better denoising results compared to the other wavelets such $\mathrm{db} 4, \mathrm{db} 10$, sym4 and coif4. However, these wavelets also give considerable accurate results.

\section{References}

Arrillaga J., Bollen M.H.J. and Waston N.R., 2000a, Power quality following deregulation, Proc. IEEE., vol. 88, no. 2, pp. 246261.

Arrillaga J., Watson N.R. and Chen.S., 2000b, Power system quality assessment, John Wiley and Sons Ltd., London.

Angrisani L., Daponte P., D’Apuuo M. and Testa A., 1996, A new wavelet transform based procedure for electrical power quality analysis, Proceedings of the International Conference on Harmonics and Quality of Power (ICHQP), Las Vegas, Nevada, USA, pp. 608-614.

Bollen Math H.J., 2000, Understanding power quality problems, IEEE Press Series on Power Engineering.

Burke J.J., Grifith D.C., and Ward J., 1990, Power quality-Two different perspectives, IEEE Trans. on Power Delivery, vol. 5, pp. 1501-1513. 
Charri O., Meunier M., and Brouaye F., 1996, Wavelets: A new tool for the resonant grounded power distribution system relaying, IEEE Trans on Power Del., vol. 11, pp. 1301-1308.

Domijan A., Heydt G.T., Meliopoulos A.P.S., Venkata S.S., and West S., 1993,Directions of research in electric power quality, IEEE Trans. on Power Delivery, vol. 8, pp. 429-436.

Dugan Roger.C., McGranaghan M.F., Santoso S. and Beaty H.W., 2003, Electrical power system quality, $2^{\text {nd }}$ Edn. McGraw Hill Book Company, New York.

Hamid E. Y. and Kawasaki Z.-I , 2002, Wavelet-based data compression of power system disturbances using the minimum description length criterion,, IEEE Trans. Power Delivery, vol. 17, no.2, pp. 460-466.

Karimi M., Mokhtari H., and Iravani M.R., 2000, Wavelet based on-line disturbance detection for power quality application, IEEE Trans.on Power Del.,vol.15, no. 10, pp. 1212-1220.

Mallat S., 1989, A theory for multiresolution signal decomposition: The wavelet representation, IEEE Trans. Pattern Anal. Mach. Intell., Vol.11, no.7, pp 674-693.

Martzloff F.D. and Gruzs T.M., 1998, Power quality site surveys: Facts, fiction, and fallacies, IEEE Trans. on Industry Application, vol. 24, pp. 1005-1018.

Michalik M., Rebizant W., Lukowicz M., Sang-Jae L., Sang- Hee K., 2006, High impedance fault detection in distribution networks with use of wavelet- based algorithm, IEEE Trans. on Power Del., vol. 21, pp.1793-1802.

Pillay P., Ribeiro P. and Pan Q., 1996, Power quality modeling using wavelets, IEEE Proceedings of the $7 *$ International Conference on Harmonics and Quality of Power (ICHQP), Las Vegas, Nevada, USA, , pp. 625-631.

Ribeiro V., Seop H. P., Romano J. M. T., and Mitra S. K., 2007, A novel MDL-based compression method for power quality applications, IEEE Trans. Power Delivery, vol. 22, no.1, pp. 27-36.

Rioul O. and Vetterli M., 1991, Wavelets and Signal Processing, IEEE Signal Processing Magazine, pp. 14-38.

Robertson D. C., Camps O.1., Mayer J. S. and Gish W.B., 1996, Wavelet and electromagnetic power system transients, IEEE Transaction on Power Delivery, Vol. 11, No 2, pp. 1050-1058.

Rodney H.G. Tan, Ramachandaramurthy V.K., 2010, Numerical Model Framework of Power Quality Events, European Journal of Scientific Research, Vol.43, pp.30-47.

Santoso S., Powers E. J., and Grady W. M., 1997, Power quality disturbance data compression using wavelet transform methods, IEEE Trans. on Power Del., vol.12, pp. 1250-1257.

Santoso S., Powers E. J., Grady W. M., and Hofmann P., 1996, Power quality assessment via wavelet transform analysis, IEEE Transaction on Power Delivery, Vol. 11, No 2, pp. 924-930.

Tunaboylu N. S. and Collins E. R., 1996, The wavelet transform approach to detect and quantify voltage sags, Proceedings of the 7” International Conference on Harmonics and Quality of Power (ICHQP), Las Vegas, Nevada, USA, pp. 619-623.

\section{Biographical notes}

D. Saxena obtained B. Tech. (Hons) in Electrical Engineering from KNIT Sultanpur (UP), India and M. Tech. in Process Control from Netaji Subhas Institute of Technology, New Delhi, India in 1999 and 2003, respectively. Presently, she is working as Associate Professor and Head, Department of Electrical and Electronics Engineering, Invertis Institute of Engineering and Technology, Bareilly. She is registered as PhD candidate in GB Technical University Lucknow, India. Her research interests are power quality, power electronics, control systems and DSP application in power.

S. N. Singh received M. Tech. and Ph.D. from Indian Institute of Technology Kanpur, India in 1989 and 1995, respectively. He is a Professor in the Department of Electrical Engineering, Indian Institute of Technology Kanpur, India. Presently he is on leave from IIT Kanpur and working with the Centre for Electric Technology (CET), Technical University of Denmark, Denmark. His research interests include power system restructuring, power system optimization \& control, voltage security and stability analysis, power system planning, and ANN application to power system problems. He is a Fellow of IE (India), Fellow of IETE (India), member IET (UK) and senior member of IEEE.

K.S. Verma received his B. Tech. (Hons) in Electrical Engineering and M. Tech. in Electrical Engineering (Power Systems) both from KNIT Sultanpur (India) in 1987 and 1998, respectively. He obtained his Ph.D. degree in Electrical Engineering (Power Systems) from Indian Institute of Technology, Roorkee, (India) in 2003. Presently, he is Director KNIT Sultanpur (India). His research interests include FACTS Technology, distributed generation, power system optimization \& control, power quality and AI application in power system.

Received January 2011

Accepted March 2011

Final acceptance in revised form April 2011 